Annu. Rev. Anim. Biosci. 2021. 9:X-X

https://doi.org/10.1146/annurev-animal-090120-115444

Copyright (C) 2021 by Annual Reviews.

All rights reserved

Peixoto et al.

www.annualreviews.org $\bullet$ Coral Probiotics

\title{
Coral Probiotics: Premise, Promise, Prospects
}

Raquel S. Peixoto, ${ }^{1,2}$ Michael Sweet, ${ }^{3}$ Helena D.M. Villela, ${ }^{1}$ Pedro Cardoso, ${ }^{1}$

Torsten Thomas, ${ }^{4}$ Christian R. Voolstra,${ }^{5,6}$ Lone Hoj, ${ }^{7}$ and David G. Bourne ${ }^{7,8}$

${ }^{1}$ Institute of Microbiology, Federal University of Rio de Janeiro, Rio de Janeiro 21941-901,

Brazil; email: raquelpeixoto@micro.ufrj.br, raquel.peixoto@kaust.edu.sa

${ }^{2}$ IMAM-AquaRio - Rio de Janeiro Aquarium Research Center, Rio de Janeiro, 20220-360 Brazil

${ }^{3}$ Aquatic Research Facility, Environmental Sustainability Research Centre, University of Derby, Derby DE22 1GB, United Kingdom

${ }^{4}$ Centre for Marine Science and Innovation, School of Biological, Earth and Environmental

Sciences, University of New South Wales, Sydney, New South Wales 2052, Australia

${ }^{5}$ Department of Biology, University of Konstanz, Konstanz 78457, Germany

${ }^{6}$ Division of Biological and Environmental Science and Engineering, Red Sea Research Center, King Abdullah University of Science and Technology, Thuwal 23955, Saudi Arabia

${ }^{7}$ Australian Institute of Marine Science, Townsville, Queensland 4810, Australia

${ }^{8}$ College of Science and Engineering, James Cook University, Townsville, Queensland 4811, Australia

[**AU: Please confirm (a) the accuracy of all affiliation information, including institutions' department names, and $(b)$ the appearance of all author names, including middle initials. Please update as needed, e.g., to match previous publications.**]

\section{Keywords}

Coral reef; environmental probiotics; Beneficial Microorganisms for Corals (BMCs); holobiont, metaorganism; microbiome.

[**AU: Please provide up to 6 keywords for search and indexing purposes.**]

Abstract 
The use of Beneficial Microorganisms for Corals (BMCs) has been proposed recently as a tool for the improvement of coral health, with knowledge in this research topic advancing rapidly. BMCs are defined as consortia of microorganisms that enhance host fitness through mechanisms that include (a) promoting coral nutrition and growth, $(b)$ mitigating stress and impacts of toxic compounds, $(c)$ controlling pathogens, and $(d)$ benefiting early life-stage development[**AU: Edit OK?ok**]. Here, we review the current proposed BMC approach and outline the studies that have proven its potential to increase coral resilience to stress. We revisit and expand the list of putative beneficial microorganisms associated with corals and their proposed mechanisms that facilitate improved host performance. Further, we discuss the caveats and bottlenecks affecting the efficacy of BMCs and close by focusing on the next steps to facilitate application at larger scales that can improve outcomes for corals and reefs globally.

\section{INTRODUCTION}

The synergistic and interdependent relationship between a macroscopic host organism and its associated microorganisms forms a metaorganism, or holobiont (see box1. Glossary for definition of these terms and other concepts) [**AU: As meant?**](1). In this relationship, the host and its microbiome act as a biological unit to constitute the resulting phenotype and maintain the fitness of the metaorganism. Corals depend on a diverse group of symbionts (2), including endosymbiotic dinoflagellates of the family Symbiodiniaceae, which reside within the gastrodermis of most shallow-water coral species ()ㅡ. These photosynthetic endosymbionts largely supply the corals' energy requirements through provision of photosynthates (4). The symbiosis between corals and their Symbiodiniaceae is the "engine of the reef" (ㅁ), facilitating construction of the coral calcium-carbonate skeleton, which constitutes the three-dimensional landscape of the reef and thus the complex habitat for thousands of other marine species ( $\underline{5})$. This delicately balanced symbiosis is threatened by ocean warming, which can trigger the loss or expulsion of Symbiodiniaceae cells, also known as bleaching (ㅁ), and, when severe, extensive coral mortality $(\underline{6}, \underline{7})$. Mass bleaching events driven by marine heatwaves are the main driver of global reef loss ( $\underline{6})$, exacerbated by local impacts such as sewage, overfishing, and disease outbreaks $(\underline{8}, \underline{9})$.

\section{Box 1. Glossary}

Microbiome: the sum of microbes in (or in a specific part of) an environment or associated with an organism, (e.g., the microbiome of a coral reef ecosystem, the 
microbiome of a coral, the microbiome of a coral compartment, such as the coral skeleton, etc.).

* Symbiosis: biological interaction between two different biological organisms. The ecological relationship of a symbiotic interaction can be mutualistic (the two organisms benefit from the relationship), commensalistic (one organism gains benefits while the other one neither benefit nor is harmed), or parasitic (one gains benefits while the other one is harmed).

* Endosymbiont: a symbiont that lives within the body or cells (intracellular) of another organism.

* Holobiont: a biological unit comprising a host and all the macro- and microorganisms that live in association with it.

Metaorganism: The synergistic and interdependent relationship between a macroscopic host organism and its associated microorganisms. The metaorganism concept focuses on the roles that each species plays on the functioning of the biological unit, which can be beneficial or detrimental.

* Microbiome manipulation: the introduction or reintroduction of microbial members to a host microbiome that affect the structure of natural microbiome (i.e. abundance, richness, etc.).

* Probiotics: live microorganisms that provide health benefits when administered to a host in adequate amounts.

* Beneficial Microorganisms for Corals (BMCs): microbial strains naturally found associated with corals that provide any kind of benefit to the metaorganism and can be considered specific probiotics for corals. BMCs can benefit the coral host itself, but can also benefit other members of the microbiome and, consequently, the whole metaorganism.

* Dysbiosis: an imbalance of the microbiome of an metaorganism that results in a disruption of the symbiotic relationship between the host and associated microorganisms.

In addition to the Symbiodiniaceae, corals harbor other groups of microorganisms that inhabit the wide variety of microhabitats provided by the host mucus, tissues, and skeleton (1013) (Figure 1). These microbes include bacteria, viruses (eukaryotic and bacteriophages), microeukaryotes, and archaea $(\underline{14}, \underline{15})$, which may be beneficial, neutral, or detrimental to coral health $(\underline{16}-\underline{18})$. Whereas the association between corals and their Symbiodiniaceae is generally 
specific (19), the relationship between corals and their bacteria is potentially more flexible and may shift in response to changing environmental conditions $(\underline{5}, \underline{18}, \underline{20})$. This flexibility provides a potential avenue for the metaorganism to acquire new traits through association with novel microbes or changes in the relative abundance of established microorganisms $(\underline{21}, \underline{22})$, a characteristic exploited in coral-probiotics approaches.

[**AU: Authors are responsible for obtaining all necessary permissions for copyrighted or previously published figures. Permission is needed even if a figure has been redrawn or substantially modified. Please also ensure that all citations, credit lines, and/or permission acknowledgments in captions are complete. If a figure is your original creation for this article (e.g., never published before), please also let us know that.**]

\section{<COMP: PLEASE INSERT FIGURE 1 HERE>}

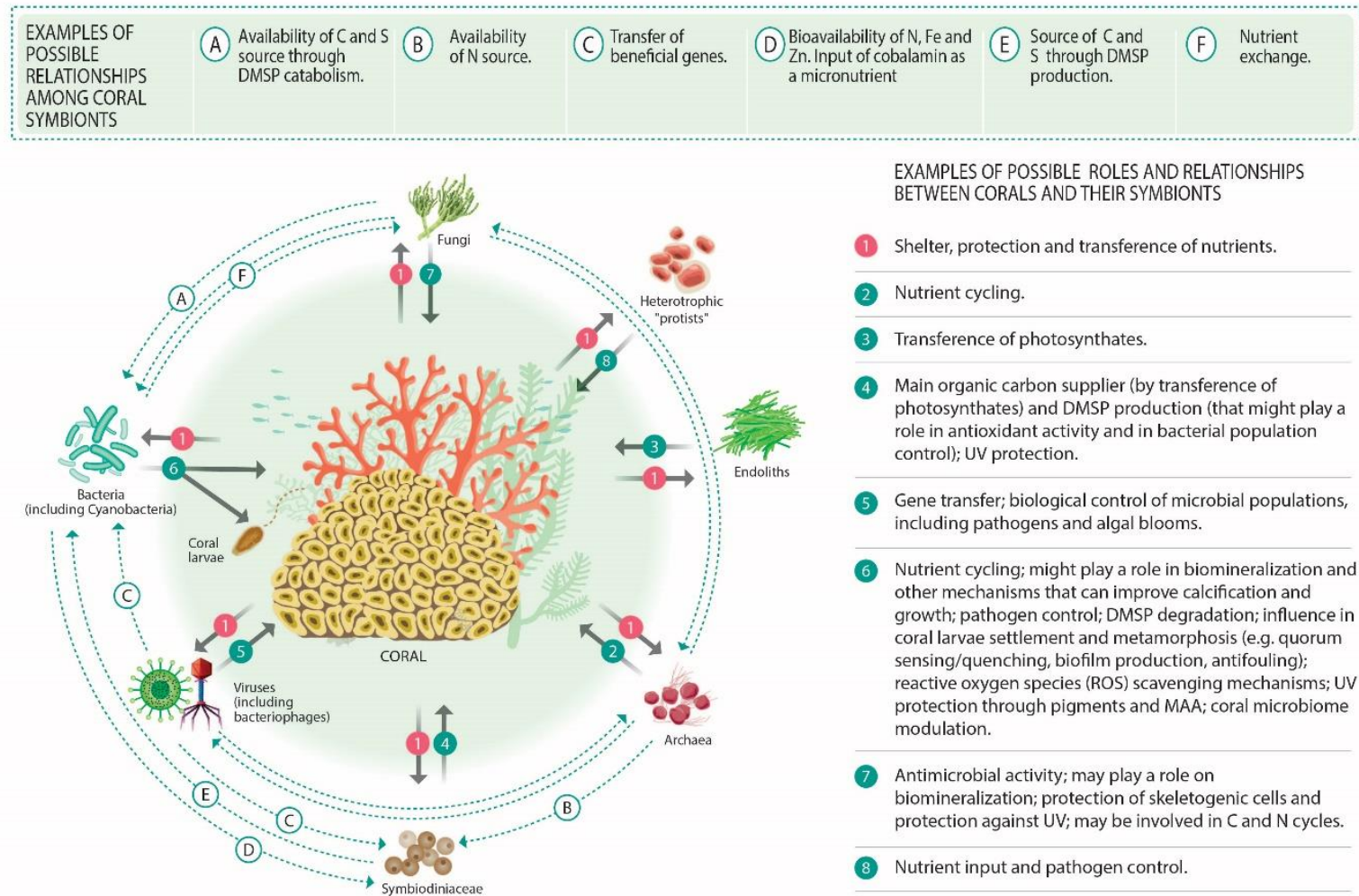

Figure 1 Possible relationships among coral symbionts and between corals and their symbionts. Abbreviations: DMSP, dimethylsulfoniopropionate; MAA, mycosporine-like amino acid.

There are currently very few known coral pathogens. Although 28 coral diseases have now been described affecting a wide variety of corals across the globe, the causative agents of only six have been described (add reference \#14 - ROSENBERG et al., 2007 - and SWEET ET AL. 2011). This is despite over 40 years of research in the field, therefore there are a number of 
significant knowledge gaps remaining concerning disease in corals in general (add reference \#16 - SWEET and BULLING, 2017). The six 'known' coral pathogens include Vibrio coralliilyticus, described as the most well characterized coral pathogen and associated with coral bleaching and white syndromes (add references Pollock et al., 2010; Ushijima et al., 2014), Serratia marcescens (cause of white pox disease - also known as Acropora Serratiosis -(add reference Sutherland et al., 2015), Pseudoalteromonas pirati (cause of Montipora white syndrome (add reference Beurmann et al., 2017), Vibrio tubiashii (cause of Porites white patch syndrome (add reference Séré et al., 2015), Vibrio shiloi (cause of bleaching in the coral Oculina patagonica (add reference Kushmaro et al., 2001)) and Thalassotalea loyana (formally Thalassomonas loyana and cause of white plague disease) (add reference Thompson et al., 2006). Nonetheless, even for these 'well described coral pathogens' there remain some inconsistencies and conflicting results among various studies.

Conversely, coral-associated microbes are also vital for the metaorganism function and health (10). Members of the microbiome play roles in energy and nutrient acquisition, reproduction, mitigation of toxic compounds, and pathogen control (add reference \#12 - Peixoto et al., 2017 - here). The increase in frequency of bleaching events and emerging coral diseases show that the disruption of the relationship between the coral host and its associated microbes is a major cause of reef deterioration $(\underline{23}, \underline{24})$, contributing to the massive loss of reef ecosystems worldwide. Hence, coral microbiology can be considered for the development of interventions for reefs conservation and restoration purposes. An example of intervention is microbiome manipulation through the use of Beneficial Microorganisms for Corals (BMCs) (12). Microbiome manipulation using beneficial native microbes approaches consist of identifying microorganisms exhibiting putatively beneficial roles for the hosts and increasing their abundances in the metaorganism, an approach that has already been widely applied in other scientific fields (25, Please add references \#28 - Woodhans et al., 2016 - and \#30 - Alberoni et al., 2016 - of the list). This type of intervention can be used to actively and specifically modulate the coral microbiome or, alternatively, to restore the microbiome to a natural/undisturbed state (18) and therefore avoid microbial dysbiosis. BMCs are, in fact, a promising strategy presenting the potential to protect natural populations of corals in the reef both before (prevention) and after (bioremediation) environmental impacts occur [**AU: Quotation marks used for purposes other than direct quotation have been removed throughout, per house style.**](12).

In this review, we present the premise and promise of the use of BMCs, discussing its original outline and summarizing the recent results obtained from BMC application in laboratory trials (see the section titled Proof of Concept). We update the framework of the selective 
screening of BMCs (see the section titled Moving Forward), including new putative beneficial mechanisms and tools to track coral symbionts, based on emerging knowledge of the processes of microbial community assembly. Finally, we discuss the prospects and next steps for overcoming limitations to the application of BMCs to corals and reefs (see the section titled Moving Beyond). [**AU: Edit OK?ok**] In Box 2, we introduce and summarize the main questions addressed in the review.

\section{BOX 2. CURRENT AND FUTURE CHALLENGES}

Challenge 1: Understanding the role of individual symbionts in coral metaorganism fitness.

- What functions do microorganisms perform to underpin coral health, how are these functions contributed (e.g., through provision of essential nutrients, metabolites, proteins, vitamins, trace metals or antioxidants), and what are the quantitative effects?

- How does environmental stress impact these symbiotic relationships, and what are the consequences for the coral metaorganism?

- Which of the many microbial taxa are necessary for metaorganism functioning versus those that are functionally redundant?

Challenge 2: Identifying, tracking, and testing possible beneficial characteristics of coralassociated microorganisms.

- What are the known and putative beneficial characteristics of these microbes? What are the main groups (taxonomic and functional) of beneficial microbes associated with corals?

- What are the best methods to track the fate of microbes in the coral mucus, tissue, and skeletal microhabitats?

Challenge 3: Developing effective BMC delivery approaches for corals.

- What are the best strategies to deliver BMCs to corals?

- What would be the best immobilization approaches to reach the target, with minimum inoculum loss and environmental impact?

- What would be the best choice for large-scale delivery?

Challenge 4: Testing strategies to apply BMCs in realistic mesocosms and ultimately on the reef.

- Are there realistic mesocosms for testing BMC delivery strategies before field inoculation?

- How will reefs be monitored after BMC inoculation? 
- What are the best coral health parameters to determine whether BMCs are benefiting corals in mesocosms and in the field?

\section{BMCS: STATE OF AFFAIRS}

Microbiome manipulation or engineering is an emerging approach to treat diseases and potentially increase the adaptability of host macroorganisms (26). Altering the host microbiome has proven effective in the treatment of several diseases in humans and wild animals and may therefore be an alternative to antibiotics and chemical therapy (27). For example, the administration of live microorganisms to benefit host health (i.e., probiotics) has been demonstrated for amphibians (28), bats (29), bees ( $\underline{30})$, and, more recently, corals $(\underline{31})$. Specifically, probiotics increased the protection of amphibians against the fungal pathogen Batrachochytrium dendrobatidis (28) and increased the survival of bats fivefold, even in field trials, in their fight against the devastating white-nose syndrome, which is also caused by a fungal pathogen ( $\underline{33})$. All these probiotics are native strains, i.e., isolated from the target hosts, and selected regarding their putative antagonims against specific pathogens (e.g., frogs, bats) or potential to support the overall metaorganism health (e.g. corals, bees, frogs). [**AU: Per house style, abbreviations/acronyms used fewer than two times have been removed, okay?ok**]

The Coral Probiotics Hypothesis $(\mathrm{CPH})$ was initially postulated to explain observations that coral health varied with changes in the microbial community composition, as well as the resistance to pathogens acquired by certain corals $(\underline{22})$. The $\mathrm{CPH}$ postulates that alterations in the abundance of microbial community members could help the coral adapt to new environmental conditions (22). An extension of this hypothesis was put forward recently, noting that the propensity for change can be denoted as microbiome flexibility, with the important caveat that the capacity for restructuring of the host-associated microbiome in light of prevailing environmental change is host specific $(\underline{18}, \underline{21})$. Hence, the extent to which hosts can adjust their microbiomes may differ, which is likely to have consequences for environmental adaptation (21). In accordance with the $\mathrm{CPH}$ and microbiome flexibility postulates, and the discussion about the biological control of coral pathogens ( $\underline{34})$, the term Beneficial Microorganisms for Corals (BMCs) was coined to describe specific microorganisms exhibiting functions that have beneficial effects on the coral metaorganism, as well as a first attempt to define strategies for their application (12). The putative beneficial functions need to be tested in vitro to develop probiotics with in vivo health benefits, including coral protection and aid in recovery from 
diseases and bleaching. This approach, which is focused not only on the mitigation of a single impact itself but also on the organisms' overall health, is based on the premise that a healthier organism will more efficiently cope with any impact. This improvement of the coral's overall health through the BMC approach can be extended by adding specific members of the probiotic consortia that can mitigate specific and local impacts. Alternatively, the use of BMCs can also be combined with other approaches, through so-called customized medicine for corals ( $\underline{35})$.

Although the initial survey proposing BMC mechanisms was published relatively recently $(\underline{12})$, the study of coral-associated microbiomes and their mechanisms of interaction has advanced greatly, and new insights have been gained. Here, we discuss the proof of concept of BMC efficiency and update the list of microorganisms and their functions that potentially enhance coral fitness, along with further research priorities.

Coral microbiome manipulation using BMCs Santos and colleagues (ㅎ6) proposed the active protection of corals from the specific environmental impact of oil through the inoculation with probiotic bacteria.[**AU: Edit OK?**ok] They demonstrated the mitigation of the effects of this contaminant via its breakdown and the consequent improvement in the health of exposed corals.[**AU: Edit OK?**ok] Rosado et al. (1), using a holistic probiotic approach, next demonstrated in laboratory trials that BMCs can increase coral resistance to thermal stress $\left(30^{\circ} \mathrm{C}\right)$ and pathogen challenge (Vibrio coralliilyticus). The study used a BMC consortium containing seven bacterial strains belonging to the genera Halomonas, Cobetia, and Pseudoalteromonas (31). The bacteria were isolated from the coral Pocillopora damicornis and selected according to functions postulated as being beneficial, according to the original list of BMC mechanisms (see 16), which included several traits, such as antagonism toward $V$. coralliilyticus, mitigation of reactive oxygen species (ROS), dimethylsulfoniopropionate (DMSP) breakdown, and nitrogen cycling. These traits were identified in the BMC candidates through biochemical and genomic screening and then assembled into a consortium. This approach was based not on a single impact or contaminant, but on the concept of restoring metaorganism homeostasis by actively removing the stress factor and facilitating the growth of the part of microbiota that is associated with coral health. During the study, $P$. damicornis nubbins treated with the BMC consortium showed a modified microbiome, as well as reduced bleaching compared with the control groups, demonstrating that addition of the BMC consortium mitigated the signs of bleaching caused by high temperatures and pathogen challenge ( $\underline{31})$.

Morgans et al. (37) recently tested the application of Symbiodiniaceae as a probiotic to corals subjected to experimental bleaching; they observed significant differences in bleaching recovery 
and mortality when Acropora millepora fragments were inoculated with Durusdinium trenchii and Cladocopium goreaui. Inoculation with $C$. goreaui resulted in significantly less bleaching than seen in control fragments and fragments inoculated with $D$. trenchii subjected to heat stress, though the inoculated Symbiodiniaceae strains were not detected in the coral tissues by ITS2 amplicon sequencing at the end of the experiment. This led the authors to suggest that these probiotics may not establish symbiosis with the corals, but instead indirectly supplement heterotrophic nutrition. However, the higher resilience to heat stress provided by $C$. goreaui compared with controls and $D$. trenchii-inoculated corals suggests that unless the corals had different feeding profiles for the two Symbiodiniaceae strains, there may be some yetunidentified benefit to the host from $C$. goreaui addition.

Microbial manipulation seems to be particularly promising in early life-history stages, when environmental microorganisms are often recruited as part of microbiome establishment and development. Damjanovic et al. (으) explored this concept recently by inoculating and tracking specific microorganisms associated with larvae of different coral species. The authors showed that it is feasible to change the microbiome of corals in early life stages by inoculating recruits with a bacterial consortium prepared in the laboratory.

Together, these attempts indicate the potential of inoculation with specific microorganisms or consortia thereof to manipulate the microbiome in different stages of coral development to improve holobiont health and resilience. Still, probiotic experiments have utilized microorganisms with potential beneficial trades countering specific stress conditions, but their roles in promoting the long-term establishment of a less vulnerable metaorganism remains unclear. The exact mechanisms that underlie the observed effects have also so far not been elucidated and remain a research priority. Identifying the mechanisms for a metaorganism's recovery, and facilitating the growth of a more resilient microbiome, will help determine the next steps for implementing probiotics in damaged coral reefs.

\section{Moving Forward}

Studies of the symbiotic relationships within coral metaorganisms have highlighted additional mechanisms that should be investigated for BMC-type applications. Here, we present an updated perspective on the use of BMCs, including new mechanisms to be explored and strategies to scale up their application.[**AU: Edit OK?**ok] The microbial functions proposed as beneficial for corals fall into four general categories: promoting coral nutrition and growth, mitigating stress and impacts of toxic compounds, providing pathogen control, and benefiting early life-stage development (Supplemental Table 1).[**Reviewer: The authors have room in 


\section{their article to include the supplemental table as part of the main text. Do you think that would be beneficial?**]}

\section{Nutrition and growth.}

Corals acquire essential macro- and micronutrients from the environment (heterotrophy) or from translocated compounds provided by their symbiotic algae or microorganisms (4). In shallowwater corals, the translocation of photosynthetic products by the associated microalgae can satisfy up to $90 \%$ of their energy demands (י), in addition to having direct effects on coral homeostasis. Additional symbionts containing photosynthesis-related genes are also found in the coral microbiome. Chromerids, also known as corallicolids $(\underline{39}, \underline{40})$, have been found to be associated with corals. These microbes are the closest free-living relatives to the Apicomplexa, a group of obligate intracellular parasites that includes causative agents of human diseases and livestock. Most apicomplexans have been shown to harbor a nonphotosynthetic plastid, called an apicoplast (41). However, the coral-associated corallicolid species Chromera velia and Vitrella brassicaformis contain chlorophyll-biosynthesis genes (느), and these organisms are the second most abundant coral-associated microeukaryotes, comprising approximately $2 \%$ of retrieved $18 \mathrm{~S}$ ribosomal RNA gene sequence reads in surveys of 38 coral species (누). The capacity of these symbionts to perform photosynthesis is debated, with speculation that corallicolids are evolutionary intermediates transitioning from phototrophy to parasitism, and further work is needed to understand their function in corals $(\underline{39}, \underline{40}, \underline{42})$. Carbon may be supplied to the coral holobiont through other metabolic pathways. For example, Robbins et al. (녀) undertook deep sequencing of the Porites lutea holobiont and identified carbon-fixation metabolic pathways in nonphototrophic Alphaproteobacteria, Nitrospirota, and Thaumarchaeota. In addition, a bacterial strain isolated from corals has been reported to host a bacteriochlorophyll gene, suggesting the potential ability for chlorophyll biosynthesis and subsequent carbon fixation through photosynthesis (44). The extent to which these other microbiome community members contribute to the total fixed carbon pool of the coral holobiont must be tested empirically.

Microbial partners likely provide other essential nutrients to corals. Both Symbiodiniaceae and coral cells lack the ability to synthesize certain vitamins, including vitamin B12 (cobalamin), which is important for many functions, such as amino acid synthesis. In corals, the concomitant high concentrations of cobalamin and bacterial cells in the gastric-cavity fluid ( $\underline{45})$ provide evidence that symbionts are delivering this essential compound to both coral cells and their dinoflagellate symbionts (나). Recent studies have shown that some coral symbionts possess genes for the production of vitamin B12, biotin, thiamin, and riboflavin $(\underline{43}, \underline{44})$. For example, 
Robbins et al. (느) identified 23 of 52 metagenome-assembled genomes derived from P. lutea that encode genes for the biosynthesis of biotin and thiamine, 41 for riboflavin, and 3 for cobalamin, further indicating that these microbes potentially underpin the holobiont function.

Several host-associated bacteria have also been shown to sequester and produce important micronutrients and trace metals, such as iron (47). Experiments exposing corals to low iron availability increased their vulnerability to thermal stress (요). Reich et al. (느) observed that low iron concentrations caused changes in the concentrations of other trace metals (e.g., zinc, copper, cobalt, manganese, nickel, molybdenum, and vanadium) within corals. Symbiodiniaceae require relatively high concentrations of iron for cell division and growth, though different clades respond differently to iron limitation, which may influence their response to environmental stresses. Certain bacterial strains produce siderophores to take up iron from the environment, forming complexes that can reenter the cells via specific receptors (9ㅗ). The potential production of siderophores by these bacterial symbionts should therefore be considered a putative BMC mechanism, as it may be a source of bioavailable iron in the coral metaorganism, because this element is usually insoluble in seawater (투).

Exploring the processes associated with calcification is another key area of research. Calcification is the process through which corals and other calcifying organisms precipitate aragonitic calcium carbonate $\left(\mathrm{CaCO}_{3}\right)$ to build their skeletons (무). Light indirectly enhances calcification ( $\underline{51}$ ) through the increase of Symbiodiniaceae photosynthesis rates. Indeed, the concomitant diversification of Symbiodiniaceae and radiation of reef-building corals ( $\underline{3})$ strongly support this photosynthetic facilitation of calcification hypothesis. Even though calcification processes in corals have been studied extensively, the mechanisms involved in the enhancement of $\mathrm{CaCO}_{3}$ deposition are not well understood. The equation summarizing the calcification process is $\mathrm{Ca}^{2+}+\mathrm{HCO}_{3}{ }^{-} \leftrightarrow \mathrm{CaCO}_{3}+\mathrm{H}^{+}$, which means that any process that increases $\mathrm{Ca}^{2+}$ and $\mathrm{HCO}_{3}{ }^{-}$and/or removes $\mathrm{H}^{+}$locally will favor the formation of $\mathrm{CaCO}_{3}$ and consequent skeleton mineralization (52). One enzyme that has the potential to contribute indirectly to the calcification process is urease. Urease catalyzes the nickel-dependent hydrolysis of urea, producing ammonia and $\mathrm{CO}_{2}$, which may direct the calcification equation toward product formation. The influence of urease on the calcification of scleractinian corals was suggested almost 45 years ago, when urease activity was detected in coral tissues with and without Symbiodiniaceae ( $\underline{53}$ ). Recent experimental evidence supports this hypothesis, with corals exposed to nickel- and urea-enriched environments showing higher rates of urea uptake and hydrolysis, which coincided with a significant enhancement of long-term calcification rates, as measured by differences in coral 
buoyant weight and estimations using the alkalinity anomaly technique in Acropora muricata and $P$. damicornis corals $(\underline{52})$. Even though the factors that significantly affect urease production at the calcification site remain unclear, some coral-associated bacteria can hydrolyze urea ( $\underline{54})$. Hence, enrichment of microorganisms with urease activity at the site of calcification may promote skeletal growth and mitigate effects such as ocean acidification.

Other microbial processes may also influence the structural integrity of the coral skeleton. For example, a peculiar interaction of symbionts residing in the coral skeleton has been reported, in which $P$. damicornis was able to associate with an inoculated fungal strain belonging to the genus Cryptococcus and which seemed to promote the survival of skeletogenic cell types (프). Although the authors suggest that this effect was not necessarily beneficial, but a way to compensate for the erosion caused by the fungus, we suggest that this microbial-mediated mechanism of supporting and recovering the coral skeleton should be investigated further in other microbial groups. Endolithic microorganisms are prevalent in the coral skeletons, structured by defined light, $\mathrm{pH}$, and nutrient and oxygen boundaries and characterized by microalgal (Osteobium spp.), fungal, and heterotrophic bacterial communities (ㄷ6). These endoliths play a role in reef erosion by dissolving calcium carbonate and weakening coral skeletons ( $\underline{56})$, though some studies have also indicated a potential for nutrient cycling and metabolite transfer, which may underpin the health of the overlying coral tissues. For example, Fine \& Loya ( $\underline{57})$ reported increases in photoassimilates transferred from endoliths to bleached coral tissues, highlighting the potential of this alternative energy source to support corals through thermal stress events. Finding ways to promote the growth of endolithic communities that support coral energy demands during periods of stress is another area of research that should be explored.

Numerous microbial-mediated mechanisms can potentially support not only the coral host but also Symbiodiniaceae growth and metabolism, and BMCs should target both. Even though Symbiodiniaceae-bacteria interactions have begun to be studied only recently, it was previously suggested that free-living bacteria can support Symbiodiniaceae nutrition and survival $(\underline{58}, \underline{59})$. The reported co-occurrence of bacteria and Symbiodiniaceae taxa (무) in coral holobiont compartments reinforces the hypothesis that these interactions can be specific and conserved. These observations have led some authors to suggest that Symbiodiniaceae may have an innate dependence on specific bacteria for exchange of nutritional resources, forming an intimate relationship that may promote optimum metabolic fitness of the coral metaorganism (61). This is further supported by the description of aragonitic spherulites that are formed by free-living Symbiodiniaceae in association with bacterial communities (므) and thus form a dinoflagellate- 
bacterial calcifying community. This aspect remains unexplored with regard to its BMC potential.

\section{Mitigation of toxic compounds and stress.}

Corals are constantly under threat of exposure to toxic compounds, including those produced directly by anthropogenic activity, such as sewage pollution and oil spills $(\underline{63}, \underline{64})$ and those produced by the coral metaorganism itself during episodes of stress ( $\underline{65})$. A wide range of microorganisms can use toxic xenobiotics as substrates $(\underline{54}, \underline{66})$ or to break down toxic metabolic products $(\underline{54}, \underline{67}) \cdot[* * \mathbf{A U}$ : Edit $\mathbf{O K} ? * * \mathbf{o k}]$ It is therefore clear that coral-associated microorganisms have the potential to mitigate coral stress in different environmental conditions.

ROS produced by corals and their endosymbiotic algae under high temperatures seem to be capable of inducing coral bleaching (65). Consequently, the production of antioxidant molecules and microbial antioxidant activity may be a beneficial function to protect heat-stressed corals $(\underline{12}, \underline{68})$, and this function includes enzymes such as catalase, peroxidase, glutathione reductase, and superoxide dismutase, which are found in many organisms (우). Although the mechanisms through which these microbial enzymes actually protect corals against oxidative stress remain to be ascertained, an exogenous addition of ROS scavengers has been shown to decrease the extent of coral bleaching (70), and corals (or their associated microbes) seem to be able to control superoxides in their immediate surroundings ( $\underline{71})$. Similarly, an increase of floridoside, a metabolite that counters ROS, as a consequence of elevated salinity levels has been demonstrated to effectively lower bleaching susceptibility [**AU: Edit OK?**](묘, $\underline{72}, \underline{73})$. The osmolytes floridoside and betaine, which are also produced by coral symbionts, may act as ROS scavengers and photoprotectors, respectively $(\underline{72}, \underline{74})$, putatively contributing to coral thermal tolerance. The production of compatible solutes commonly used for osmotic protection by coral-associated microorganisms is especially interesting in the context of heat stress, owing to similarities between ROS-producing mechanisms in photoautotrophic organisms under stressful salinity and heat conditions $(\underline{72}, \underline{75})$.

In addition to enzymatic defenses against oxidative stress, the damage from ROS can also be controlled in photosynthetic organisms through the use of photoprotective compounds (므). These compounds could mitigate the damage done to the photosystems of coral-associated algae and consequently reduce ROS production.[**AU: Edit OK?ok**] Mycosporine-like amino acids have been identified in taxonomically diverse coral species and have been dubbed "natural sunscreens" owing to their capacity to absorb UV radiation, whereas others are better known for their antioxidant activities (77). They have also been detected in marine heterotrophic bacteria, 
cyanobacteria, and microalgae (77), and coral symbionts can produce these molecules (8) . Carotenoids are another group of molecules with well-documented antioxidant and photoprotective properties in photoautotrophs $(\underline{79})$, including Symbiodiniaceae algae (무). Coralassociated bacteria such as Erythrobacter spp. have been found to contain large amounts of carotenoids and have been proposed to mitigate heat stress-related production of ROS in the coral metaorganism $(\underline{81})$.

Other solutes have also been associated with the mitigation of heat and oxidative stress in corals. DMSP, for example, is an osmolyte found in many species of marine algae, including members of the Symbiodiniaceae $(\underline{43}, \underline{82})$. DMSP and its breakdown products (dimethylsulfide, acrylate, dimethyl sulfoxide, and methanesulfinic acid) have been found to scavenge different types of ROS in marine algae ( $\underline{83})$. The changes in DMSP levels in corals owing to copper exposure may [**AU: "may"?**]be linked to the antioxidant function of the solute (2) $)$. DMSP produced by coral-associated algae may therefore benefit corals because of its antioxidant role. However, an excess of DMSP can also trigger (or be involved in) dysbiotic processes, as discussed in more detail below. The activities of coral-associated microorganisms can also

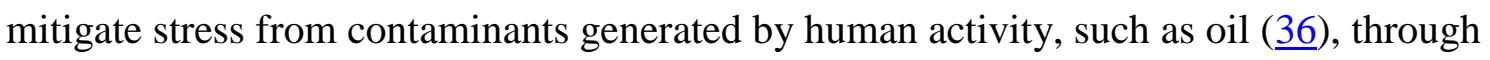
breakdown of these compounds within corals or in the surrounding environment in direct contact with the metaorganism.

\section{Pathogen control.}

Microorganisms found in corals can produce antimicrobial compounds, which can be important for structuring coral microbial communities and are potentially beneficial to host health $(\underline{84}, \underline{85})$. Competition between pathogens and symbiotic microorganisms occurs in corals $(\underline{85}, \underline{86})$, and selection of microorganisms antagonistic to known coral pathogens can be useful in applying BMCs to corals at risk of diseases. Some examples of possible roles and relationships between corals and their symbionts are summarized in Figure 1 and Table 1 [**AU: Supplemental Table

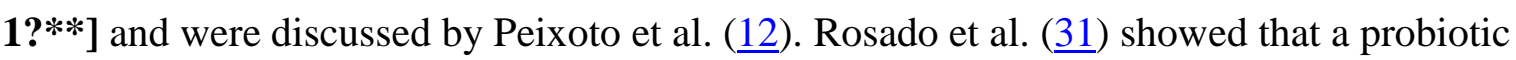
consortium tested in aquarium experiments successfully protected coral nubbins against infection by the pathogen $V$. coralliilyticus, and different mechanisms inherent to native microorganisms have been suggested to promote the biological control of this pathogenic organism.[**AU: Edit OK?**ok]

Production of DMSP by coral endosymbiotic algae can structure coral-associated microbial communities by supporting bacteria that can metabolize DMSP, DMS, and acrylic acid (7ㅡ). This metabolic potential includes bacteria from the genus Roseobacter; many of these bacteria 
possess antimicrobial properties (e.g., production of thiotropocin) that may aid the corals in resisting pathogens ( $\underline{88})$. Breakdown of DMSP can therefore be viewed as a possible BMC characteristic. Further, differences in $\mathrm{pH}$ found between the coral mucus $(\sim 7.7)$ and the surrounding seawater ( 8.3) have been hypothesized to result from the presence of high concentrations of DMSP breakdown products (DMS and acrylate), which might also prevent initial colonization by potential pathogens (7) . Furthermore, DMSP has been discovered to drive chemotaxis and chemokinesis in the coral pathogen $V$. corallillyticus, and attraction of this pathogen to $P$. damicornis has been demonstrated, with a stronger chemical cue directing the bacteria to heat-stressed corals (9ㅜ). DMS, however, has been shown to provoke only a very weak chemotaxis in $V$. coralliilyticus $(\underline{89})$, and the other products of DMSP breakdown have not yet been explored in relation to chemotaxis.

Quorum sensing (QS) cell-cell signaling enables bacteria to communicate with one another via autoinducers and to control the expression of characteristics associated with antibiotic production, biofilm formation, and pathogenesis (이). This type of communication has been suggested to be used in pathogenic and mutualistic interactions within coral-associated microbial communities (90), and study of QS in corals has revealed that it may participate in different coral diseases. Among the autoinducer substances known to participate in QS are the acyl-homoserine lactones (AHLs), which are produced by different coral-associated vibrios, including the coral pathogens V. coralliilyticus, Vibrio shiloi, and Vibrio harveyi (91). AHL signaling has been related to coral diseases and is linked to the structuring of bacterial communities and disease progression in Diploria strigosa corals infected with black-band disease (92). In Acropora cervicornis, the addition of exogenous AHLs produced symptoms similar to those of white-band disease and, in conjunction with a healthy coral homogenate, was able to act as a disease-causing agent (93). Aquarium experiments with $P$. damicornis also found evidence for a relationship between AHL regulation and coral-bleaching progression, because corals treated with exogenous AHLs and AHL-producing bacteria were more susceptible to bleaching and displayed more significant changes in their bacterial community compositions than control groups treated with the same substances with the addition of a QS inhibitor (94). This suggests that the inhibition of QS or the breakdown of QS autoinducers such as AHLs may be a potential BMC characteristic that protects corals from pathogens and bleaching $(\underline{12}, \underline{90}, \underline{95})$.

Top-down control of coral pathogens may also benefit the host. This biological control can be performed by viruses capable of infecting disease-causing agents or by natural predators. Phages associated with the coral mucus layer have been posited to provide a first line of immunity against bacterial pathogenesis and are also suggested to regulate coral-associated 
microbial communities (므). The use of phage therapy as a method to control coral diseases has been increasingly discussed in recent years, and the positive aspects of this method of biological control, such as target specificity, replication, and safety, have been highlighted previously ( $\underline{34}$, 97). Treatments using phages able to infect the coral pathogens V. coralliilyticus and Thalassomonas loyana $(\underline{97}, \underline{98})$ could ameliorate disease symptoms or stop disease transmission in aquarium experiments, and manipulation of bacteriophages can be regarded as a potentially useful tool against coral disease.

Pathogen predators are also a self-replicating potential solution for coral infections, capable of mediating microbial communities associated with the host (99). Bacterivory by microeukaryotes and predatory bacteria is postulated to regulate microbial communities in different aquatic ecosystems via selective foraging $(\underline{100}, \underline{101})$. In corals, studies of microbial predation found that the bacteria Halobacteriovorax could prey on the coral pathogens $V$. coralliilyticus and $V$. harveyi in plaque assays (102). Furthermore, inoculation of Halobacteriovorax in aquarium experiments prevented the increase of $V$. coralliilyticus in corals and stabilized the rest of the host's microbiome, also preventing blooming of opportunistic bacteria in stressful temperatures (99). These studies highlight the importance of predatory bacteria for the structuring of coral microbiomes and also demonstrate the potential to manipulate pathogen predators to protect against disease.

\section{Early life development.}

Sexual reproduction in coral results in a swimming larva or planula that acquires microbial communities either horizontally from the environment $(\underline{103})$ or inherited vertically from the parental gametes (104). [**AU: Authors missing. Please clarify**]Apprill et al. (ADD TO THE LIST) investigated the bacterial colonization of planulae derived from the spawning species Pocillopora meandrina and observed internalized bacteria after $79 \mathrm{~h}$, indicating likely horizontal transfer. These bacteria were affiliated with the Roseobacter clade, many members of which possess antimicrobial traits, which may benefit the early coral life stages by excluding pathogens. Investigation of the broadcast-spawning coral Acropora tenuis also showed a lack of internalized bacteria in the offspring, though mucus surrounding these early life stages was colonized by members of Rhodobacteraceae, Alteromonadaceae, and Oceanospirillaceae (38). In contrast, the brooding coral Porites astreoides was demonstrated to vertically transmit members of the Roseobacter clade to their planulae, and these associates were maintained in settled juveniles (105). Similarly, Damjanovic et al. (106) found that larvae and recruits of the brooding coral Pocillopora acuta inherited not only Symbiodiniaceae cells from the parents but 
also bacteria from the family Rhodobacteraceae and the genus Endozoicomonas (both phylum Proteobacteria). Ceh et al. (107) investigated the seawater surrounding broadcast and brooding coral species after release of their gametes and planulae, found increases of members of Alteromonas and Roseobacter, and suggested that this increase may aid in transfer of beneficial microorganisms to the offspring. Diazotrophs have also been reported associated with the early life stage of A. millepora corals, potentially supporting nitrogen demand in developmental stages prior to the uptake and establishment of Symbiodiniaceae populations (108). The early life stages of corals are influenced by their symbionts; for example, the nutrition provided by Symbiodiniaceae is essential to the success of newly settled recruits. However, the influence of other members of the microbiome, such as the apicomplexan-like C. velia, bacterial and archaeal communities, on the fitness of early life stages is still unclear.[**AU: Please recast sentence for clarity**]

Bacterial surface biofilms have been found to facilitate the settlement of some coral larvae. For example, a Pseudoalteromonas strain (a genus that includes members able to produce a biofilm) was isolated from crustose coralline algae (CCA)[**AU: Spell out/define?**] and shown to induce metamorphosis of coral larvae of the genus Acropora $(\underline{109}, \underline{110})$. Sneed et al. $(\underline{110})$ also found that a strain of Pseudoalteromonas [**AU: Correct, per

reference?**ok]isolated from marine biofilms induced metamorphosis of $P$. astreoides, Orbicella franksi, and Acropora palmata larvae; they attributed this effect to the derived bacterial compound tetrabromopyrrole. However, it is unlikely that tetrabromopyrrole is the only compound produced by strains of Pseudoalteromonas able to induce metamorphosis.

Pseudoalteromonas luteoviolacea, for example, produces ordered arrays of phage tail-like metamorphosis-associated contractile structures that induce metamorphosis in larvae of the tubeworm Hydroides elegans (111). Though several reports have corroborated the importance of biofilm-forming microbes for coral settlement, metamorphosis, and recruitment, the signaling steps that underpin these processes remain elusive. Many Pseudoalteromonas and other biofilmforming species have also been found to live in association with adult corals ( $\underline{31})$, suggesting that adult corals act as a reservoir of biofilm-forming microbial species, which are constantly exchanged with the reef environment to support coral recruitment. Non-biofilm-forming bacteria that support the growth of biofilm-forming strains have been shown to increase settlement of other marine invertebrate species (112). The processes that promote coral settlement are complex, though the roles of microbial biofilms, chemical cues, and cell-cell communication require further investigation and may be part of the BMC framework.

The four categories of beneficial mechanisms - coral nutrition and growth, mitigation of 
stress and toxic compounds, pathogen control, and early life development—can act synergistically to benefit corals. For example, microbial nitrogen fixation serves as a nitrogen input for the metaorganism, alongside heterotrophy, and is an important source of nutrients for both corals and Symbiodiniaceae $(\underline{113}, \underline{114})$. The activity of microbial enzymes that participate in other phases of nitrogen cycling can help to control its distribution in the metaorganism, limiting nitrogen entry into the Symbiodiniaceae and controlling pathogens and the symbiosis between algae and corals [**AU: As meant?**ok] $(\underline{113}, \underline{114})$. In parallel, corals living in waters with excess dissolved inorganic nitrogen have shown greater susceptibility to thermal stress (115), indicating the potential importance of microorganisms that cycle this element for protection against bleaching (mitigation of stress or toxic compounds). Nutritional balance within the coral holobiont is important, as both an excess and a limitation of essential nutrients can destabilize the delicate symbiosis and ultimately harm the metaorganism.

\section{Identifying Putative BMC Molecular Markers}

A wide range of coral-associated and free-living marine bacteria possess putative beneficial traits. This raises the question of how to discriminate a symbiont from opportunistic organisms found associated with coral, in particular, compounded by the notion that the metaorganism assemblage by default is fluid, i.e., dynamic across space and time [sensu Jaspers et al. (116)]. The molecular signatures of symbionts might be helpful in screening. For example, in insects, symbionts can be sequestered in bacteria-bearing host cells, called bacteriocytes, which in some species cluster together to form a bacteriome (117). Similar clusters, termed coral-associated microbial aggregates (CAMAs), are observed in corals $(\underline{13}, \underline{118})$. In insects, antimicrobial peptides, such as coleoptericin-A from weevils, also selectively target endosymbionts within the bacteriocytes and inhibit their cell division (119). If the synthesis of coleoptericin-A is blocked, the bacteria escape from the bacteriocytes and spread into surrounding tissues, which is detrimental to the host. In this example, it seems that the coevolution of host and symbiont has enabled the immune system to facilitate the endosymbiotic relationship. In corals, we still do not know if the CAMAs are beneficial or detrimental to the coral metaorganisms, though many are dominated by Endozoicomonas-affiliated taxa (13). How the coral regulates the composition and abundance of these CAMAs needs investigation, with a view to determining whether they can be modulated to benefit host fitness.

Bacterial symbionts of corals have recently been found to be enriched in genes encoding for eukaryotic-like proteins (ELPs), compared with planktonic bacteria (푸). ELPs often contain characteristic repeat domains, such as the ankyrin repeat (ANK) or the WD40-repeat, which are 
involved in mediating protein-protein interactions $(\underline{43}, \underline{120})$. These proteins and domains, as the name suggests, are frequently found in eukaryotes but are also increasingly found and recognized in bacteria and archaea, in particular those with a pathogenic or symbiotic lifestyle (121). ELPs can modulate cellular processes in their host; recent work has shown that ANK-type ELPs found in sponge symbionts can interfere with the phagocytosis of eukaryotic cells $(\underline{122}, \underline{123})$. This likely helps symbionts to escape phagocytosis in filter-feeding sponges or allows bacteria to persist intracellularly (e.g., in bacteriocytes), similarly to what has been shown for ANK proteins secreted by Legionella pneumophila, which allow for intracellular persistence in macrophages $(\underline{124}, \underline{125})$. Genes for ANK and WD40-type proteins were present and often abundant in all major bacterial symbiont clades found in the coral $P$. lutea ( $\underline{43})$, indicating that these genes may be generally important for mediating symbiotic interactions with corals. We therefore suggest that ELPs could be used as molecular markers to distinguish a BMC candidate from allochthonous bacteria.

\section{Moving Beyond: Challenges and Potential Solutions}

BMC studies performed to date have relied upon delivery of free cells into the water column or onto coral nubbins held in small-scale laboratory trials or aquaria systems $(\underline{31}, \underline{36}, \underline{38})$. In these smaller systems, free cells may become trapped in coral mucus and possibly transferred to other compartments directly via ingestion of suspended cells or the mucus-entrapped BMCs, although this still needs to be documented directly. The current lack of strategies to effectively scale up the application of BMCs from laboratory trials to the field is a crucial bottleneck to be addressed. Nonetheless, we believe that comparisons to the successful development and deployment of microorganisms in other aquatic systems can offer invaluable insights that can be tested and extrapolated to coral reefs.

In practice, delivery of microorganisms in aquatic systems is a major challenge, owing to direct dilution and water currents, as well as interactions with a wide range of naturally occurring micro- and macroorganisms. In aquaria and aquaculture tanks with limited water volume and controlled flow, the dilution issue can be resolved; however, in open aquatic systems such as oceans, innovative strategies need to be developed. One of the approaches that might be adopted to address this problem is immobilization of the cells.

Immobilization of microbial cells to enhance delivery efficiency is used in several industries, such as wine production $(\underline{126})$, biofuel production $(\underline{127})$, and pollutant/waste remediation $(\underline{128}$, 129). Immobilization of cells offers numerous advantages, including maintenance of their metabolic activity owing to better-controlled chemical conditions and physical protection. Also, 
slow release of cells from a solid support can reduce the need for constant reinoculation. Additionally, immobilized cells will disperse less widely compared with free-living cells, thereby effectively reducing potential issues concerning escaped microorganisms affecting or interacting with nontarget organisms $(\underline{130})$.

The selection of a carrier is a crucial step in immobilization strategies. Desirable characteristics include low cost, nontoxicity, high carrying capacity, permeability to growth substrates, and ease of preparation and handling (131). In the case of BMCs, it should be possible to break down the carrier naturally or to regenerate it. Microorganisms can be immobilized in carriers made from three types of material: inorganic, organic, or a composite of both (128). Organic carriers include naturally occurring products (e.g., coconut husk, chitin, alginate, agar, and guar gum) and synthetic polymers (e.g., polypropylene, polyurethane, and acrylamide). Inorganic carriers include charcoal, clay, silica, ceramics, and celite, among others (132). Whereas inorganic carriers are usually more resistant, less costly, and easier to handle and reuse, organic carriers are more adaptable and typically biocompatible and therefore safer for other organisms (133). Composite carriers, which combine the advantages of both organic and inorganic carriers, provide some level of compromise between these respective (dis)advantages and include substances such as polyvinyl alcohol, sodium alginate, and polyvinyl alcohol-guar $\operatorname{gum}(\underline{128}) .[* * \mathbf{A U}:$ Edit OK?**ok]

Cells can attach strongly or loosely to the carrier's surfaces or internal pores via mechanisms such as adsorption, entrapment, and encapsulation. The mechanisms that microorganisms use to attach to surfaces are well studied (134) and can thus be used to select suitable surfaces.

Entrapment, where cells are trapped within a support matrix, has the advantage that cells are confined inside a solid matrix, which provides resistance to physical, chemical, or biological impacts. This method also allows the entrapment of high densities of cells that can be released slowly and continuously. The matrix most often used for entrapment immobilization is the polymer alginate (128). Microencapsulation of living cells is a type of entrapment in which the cells are enclosed by a semipermeable membrane (128). The main advantage of microencapsulation systems is that the entrapment fluid can offer optimal conditions for cell function.

Another option is bioencapsulation, where living carriers, such as the live feed organisms Artemia spp.,[**AU: spp.?**ok] rotifers, or copepods, are used to successfully deliver nutrients, immune stimulants, and probiotics to several aquatic organisms $(\underline{135}, \underline{136})$. Live feeds have high palatability and digestibility and can stimulate a natural feeding response in animals (137). Nevertheless, for many established aquaculture finfish species, coating of formulated feeds with 
probiotics is the most common delivery strategy, as they offer precise control of nutritional components and ease of preparation and application $(\underline{137}, \underline{138})$.

Application of BMCs in aquaculture facilities and the field has been proposed to produce healthy and resilient coral larvae, juveniles, or adults for reef-restoration purposes. Adapting the immobilization methods discussed above (or developing novel ones) for use with coral probiotics not only is possible (Figure 2) but is a gap that urgently needs to be filled. Among the carrier materials discussed above, biocompatible polymers and live feed organisms seem to possess the required characteristics to deliver coral probiotics both in aquaria and in the field. The development of customized carriers that specifically attach to coral structures is desirable for successful application on the reef, but this would require detailed understanding of the chemical composition and biological characteristics of such structures. Aquaria-based experiments will be helpful during initial development and testing of delivery strategies appropriate for different coral species and life stages. Application in aquaria and aquaculture facilities is inherently easier than field application, given that water volumes and flow rates can be controlled, the costs and logistical requirements for repeat applications are lower, and there is no risk of delivery to nontarget organisms. A transition to field applications will likely have to occur via controlled testing in large mesocosm systems that aim to replicate processes on coral reefs.

\section{<COMP: PLEASE INSERT FIGURE 2 HERE>}

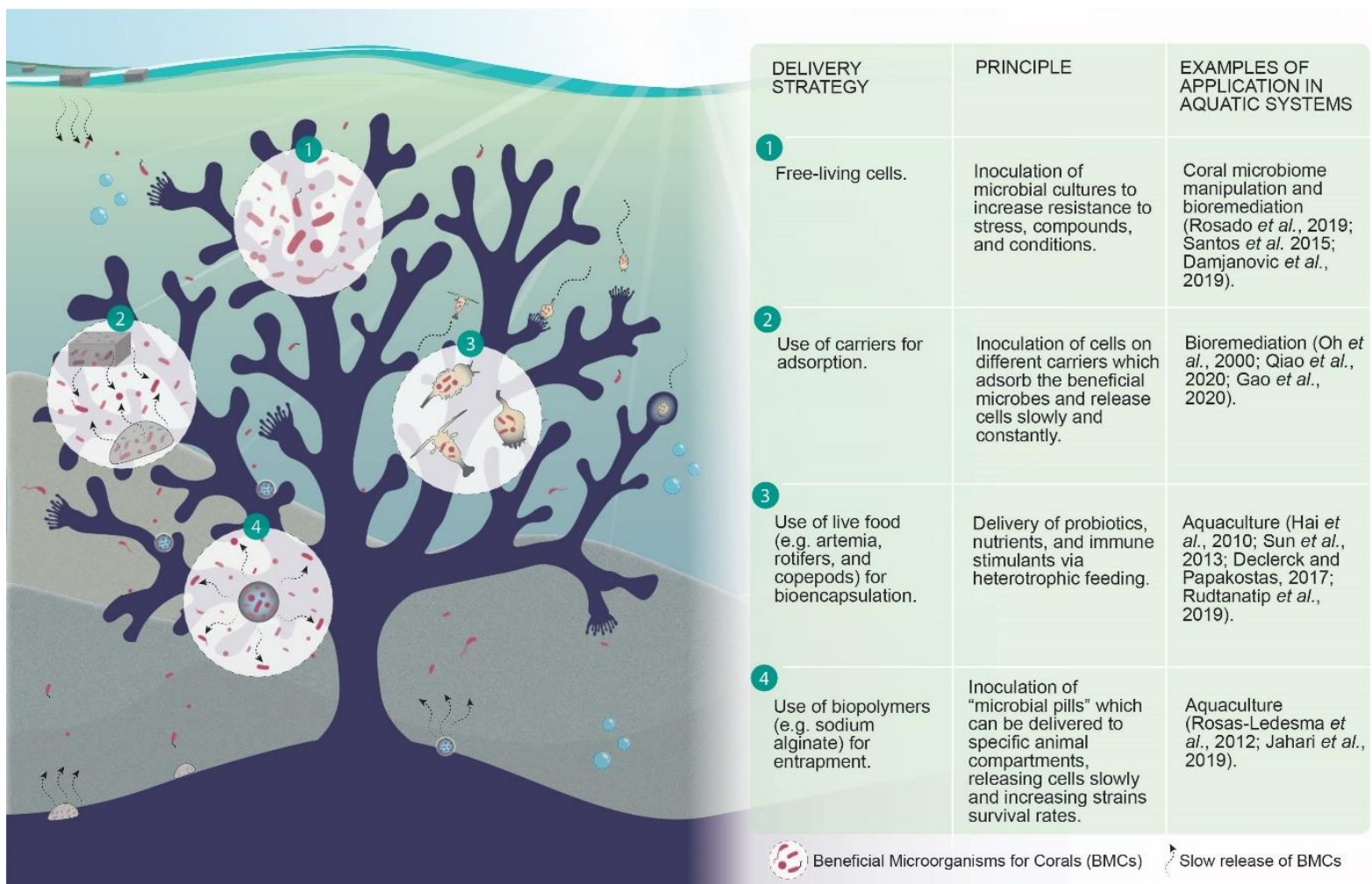


Figure 2 Examples of delivery strategies to be explored for the deployment of Beneficial Microorganisms for Corals (BMCs) in the field and examples of their applications in aquatic systems. [**AU: Please add Oh et al. 2000, Qiao et al. 2020, Gao et al. 2020, Hai et al. 2010, Sun et al. 2013, Rosas-Ledesma et al. 2012, Jahari et al. 2019 to lit cited ${ }^{* * *}$ ]

\section{CONCLUSIONS}

The manipulation of coral microbiomes through the administration of BMCs, i.e., probiotics specifically selected for corals, has emerged recently as a promising tool to explore coralmicrobiome symbiotic relationships and, ultimately, to ameliorate impacts on corals and reefs. The new knowledge being generated in the field of coral probiotics can be further extrapolated to support the development of probiotics for other threatened wildlife. The ability to manipulate the microbiome will allow us to explore the location of symbionts within the host, as well as the mechanisms of symbiotic interaction that can help to elucidate key questions in coral biology, such as the importance of partner fidelity and the transmission of symbionts. The recent advancements in aquarium methods and facilities that allow research laboratories to predictably spawn scleractinian corals (139) will greatly facilitate studies of microbial uptake and establishment in early life stages of corals. The use of fluorescence in situ hybridization and advanced imaging approaches linked with stable isotope labeling techniques may facilitate the understanding of BMC interactions within the host (140). An alternative approach to be explored is the use of fluorescently labeled bacterial cells or fluorescent latex beads (141) to visualize and track the uptake and establishment of BMCs delivered to early and late life stages. This approach has the advantage of enabling visualization in live specimens with intact mucus layers, and live, labeled bacteria can be enumerated by agar plating to complement direct microscopy observations. Because of the genetic manipulation needed, such approaches are not field deployable and should be restricted to experiments studying underlying BMC mechanisms or optimizing delivery strategies. Solutions to the above can, in turn, provide novel or complement existing tools to improve BMC uptake and stability. In a nutshell, the ability to successfully manipulate host-microbial associations also requires an intricate knowledge of the processes that govern these interactions. Therefore, the field is knowledge generating and knowledge applying. Regarding the application of BMCs in reefs, delivery of free cells is probably unrealistic, and an optimized immobilization approach will be required. Possible delivery strategies include the deployment of slow-release devices and targeted underwater or surface release of BMCs immobilized in feed items (live feeds, feed aggregates or pellets, encapsulated feeds), adsorbed to a solid carrier or entrapped in a supporting matrix. Discussion of such strategies should 
involve an environmental risk assessment with local government and community involvement and should also consider the costs versus benefits of applying these measures to protect coral reefs. Finally, an understanding and admission that many, if not all, reef ecosystems have already changed in response to local and global impacts needs to be taken to heart and the goal of any restoration measure clearly stated from the onset.

[**AU: PLEASE INSERT YOUR DISCLOSURE OF POTENTIAL BIAS STATEMENT, COVERING ALL AUTHORS, HERE. IF YOU HAVE NOTHING TO DISCLOSE, PLEASE CONFIRM THAT THE STATEMENT BELOW MAY BE PUBLISHED IN YOUR REVIEW. FILL OUT AND RETURN THE FORMS SENT WITH YOUR GALLEYS, AS MANUSCRIPTS CANNOT BE SENT FOR PROOF LAYOUT UNTIL THESE FORMS ARE RECEIVED.**]

\section{DISCLOSURE STATEMENT}

The authors are not aware of any affiliations, memberships, funding, or financial holdings that might be perceived as affecting the objectivity of this review.

\section{ACKNOWLEDGEMENTS}

This literature review was carried out in association with the ongoing R\&D project registered as ANP 21005-4, "PROBIO-DEEP - Survey of potential impacts caused by oil and gas exploration on deep-sea marine holobionts and selection of potential bioindicators and bioremediation processes for these ecosystems" (UFRJ/Shell Brasil/ANP), sponsored by Shell Brasil under the ANP R\&D levy as "Compromisso de Investimentos com Pesquisa e Desenvolvimento". Torsten Thomas would like to acknowledge support by the Betty and Gordon Moore Foundation and the Australian Research Council.

\section{[**AU: WOULD YOU LIKE TO ADD AN ACKNOWLEDGMENTS SECTION? THIS IS THE FINAL OPPORTUNITY TO DO SO.**]}

\section{LITERATURE CITED}

1. Bosch TCG, McFall-Ngai MJ. 2011. Metaorganisms as the new frontier. Zoology 114:185-90

2. Bang C, Dagan T, Deines P, Dubilier N, Duschl WJ, et al. 2018. Metaorganisms in extreme environments: Do microbes play a role in organismal adaptation? Zoology 127:1-19

3. LaJeunesse TC, Parkinson JE, Gabrielson PW, Jeong HJ, Reimer JD, et al. 2018. Systematic revision of Symbiodiniaceae highlights the antiquity and diversity of coral endosymbionts. Curr. Biol. 28:2570-80.e6

4. Muscatine L. 1990. The role of symbiotic algae in carbon and energy flux in reef corals. Coral 
Reefs 25(1.29): [**AU: Please provide page numbers**]

5. Pogoreutz C, Voolstra C, Rädecker N, Weis V, Cardenas A, Raina J-B. 2020. The coral holobiont highlights the dependence of cnidarian animal hosts on their associated microbes. In Cellular Dialogues in the Holobiont, ed. T Bosch, M Hadfield[**AU: Please provide page numbers**]. Boca Raton, FL: CRC Press

6. Hughes TP, Anderson KD, Connolly SR, Heron SF, Kerry JT, et al. 2018. Spatial and temporal patterns of mass bleaching of corals in the Anthropocene. Science 359(6371):80-83

7. Duarte GAS, Villela HDM, Deocleciano M, Silva D, Barno A, et al. 2020. Heat waves are a major threat to turbid coral reefs in Brazil. Front. Mar. Sci. 7:179

8. Zaneveld JR, Burkepile DE, Shantz AA, Pritchard CE, McMinds R, et al. 2016. Overfishing and nutrient pollution interact with temperature to disrupt coral reefs down to microbial scales. Nat. Commun. 7:1-12

9. Sweet M, Burian A, Fifer J, Bulling M, Elliott D, Raymundo L. 2019. Compositional homogeneity in the pathobiome of a new, slow-spreading coral disease. Microbiome 7:139

10. Putnam HM, Barott KL, Ainsworth TD, Gates RD. 2017. The vulnerability and resilience of reef-building corals. Curr. Biol. 27(11):R528-40

11. O’Brien PA, Morrow KM, Willis BL, Bourne DG. 2016. Implications of ocean acidification for marine microorganisms from the free-living to the host-associated. Front. Mar. Sci. 3:47

12. Peixoto R, Rosado PM, de Assis Leite DC, Rosado AS, Bourne DG. 2017. Beneficial Microorganisms for Corals (BMC): proposed mechanisms for coral health and resilience. Front. Microbiol. 8:341

13. Neave MJ, Rachmawati R, Xun L, Michell CT, Bourne DG, et al. 2017. Differential specificity between closely related corals and abundant Endozoicomonas endosymbionts across global scales. ISME J. 11:186-200

14. Rosenberg E, Koren O, Reshef L, Efrony R, Zilber-Rosenberg I. 2007. The role of microorganisms in coral health, disease and evolution. Nat. Rev. Microbiol. 5:355-62

15. Bourne DG, Morrow KM, Webster NS. 2016. Insights into the coral microbiome: underpinning the health and resilience of reef ecosystems. Annu. Rev. Microbiol. 70:317-40

16. Sweet MJ, Bulling MT. 2017. On the importance of the microbiome and pathobiome in coral health and disease. Front. Mar. Sci. 4:9

17. Ziegler M, Seneca FO, Yum LK, Palumbi SR, Voolstra CR. 2017. Bacterial community dynamics are linked to patterns of coral heat tolerance. Nat. Commun. 8:14213

18. Ziegler M, Grupstra CGB, Barreto MM, Eaton M, BaOmar J, et al. 2019. Coral bacterial community structure responds to environmental change in a host-specific manner. Nat. 
Commun. 10:3092

19. Hume BCC, Mejia-Restrepo A, Voolstra CR, Berumen ML. 2020. Fine-scale delineation of Symbiodiniaceae genotypes on a previously bleached central Red Sea reef system demonstrates a prevalence of coral host-specific associations. Coral Reefs 39:583-601

20. Röthig T, Ochsenkühn MA, Roik A, Van Der Merwe R, Voolstra CR. 2016. Long-term salinity tolerance is accompanied by major restructuring of the coral bacterial microbiome. Mol. Ecol. 25(6):1308-23

21. Voolstra CR, Ziegler M. 2020. Adapting with microbial help: Microbiome flexibility facilitates rapid responses to environmental change. BioEssays 42(7):2000004

22. Reshef L, Koren O, Loya Y, Zilber-Rosenberg I, Rosenberg E. 2006. The coral probiotic hypothesis. Environ. Microbiol. 8(12):2068-73

23. Bourne DG, Garren M, Work TM, Rosenberg E, Smith GW, Harvell CD. 2009. Microbial disease and the coral holobiont. Trends Microbiol. 17(12):554-62

24. Mera H, Bourne DG. 2018. Disentangling causation: complex roles of coral-associated microorganisms in disease. Environ. Microbiol. 20(2):431-49

25. Saharan BS, Nehra V. 2011. Plant growth promoting rhizobacteria: a critical review. Life Sci. Med. Res. 21:1-30

26. West AG, Waite DW, Deines P, Bourne DG, Digby A, et al. 2019. The microbiome in threatened species conservation. Biol. Conserv. 229:85-98

27. McKenzie VJ, Kueneman JG, Harris RN. 2018. Probiotics as a tool for disease mitigation in wildlife: insights from food production and medicine. Ann. N.Y. Acad. Sci. 1429(1):18-30

28. Woodhams DC, Bletz M, Kueneman J, McKenzie V. 2016. Managing amphibian disease with skin microbiota. Trends Microbiol. 24(3):161-64

29. Cheng TL, Mayberry H, McGuire LP, Hoyt JR, Langwig KE, et al. 2017. Efficacy of a probiotic bacterium to treat bats affected by the disease white-nose syndrome. J. Appl. Ecol. 54(3):701-8

30. Alberoni D, Gaggìa F, Baffoni L, Di Gioia D. 2016. Beneficial microorganisms for honey bees: problems and progresses. Appl. Microbiol. Biotechnol. 100(22):9469-82

31. Rosado P, Leite DCA, Duarte GAS, Chaloub RM, Jospin G, et al. 2019. Marine probiotics: increasing coral resistance to bleaching through microbiome manipulation. ISME J. 13:92136

32. Vredenburg VT, Briggs CJ, Harris RN. 2011. Host pathogen dynamics of amphibian chytridiomycosis: the role of the skin microbiome in health and disease. [**AU: Please provide publication information**] 
33. Hoyt JR, Langwig KE, White JP, Kaarakka HM, Redell JA, et al. 2019. Field trial of a probiotic bacteria to protect bats from white-nose syndrome. Sci. Rep. 9(9158):1-9

34. Teplitski M, Ritchie K. 2009. How feasible is the biological control of coral diseases? Trends Ecol. Evol. 24(7):378-85

35. Peixoto RS, Sweet M, Bourne DG. 2019. Customized medicine for corals. Front. Mar. Sci. $6: 1-5$

36. Santos HF, Duarte GAS, da Costa Rachid CT, Chaloub RM, Calderon EN, et al. 2015. Impact of oil spills on coral reefs can be reduced by bioremediation using probiotic microbiota. Sci. Rep. 5:18268

37. Morgans CA, Hung JY, Bourne DG, Quigley KM. 2020. Symbiodiniaceae probiotics for use in bleaching recovery. Restor. Ecol. 28(2):282-88

38. Damjanovic K, van Oppen MJH, Menéndez P, Blackall LL. 2019. Experimental inoculation of coral recruits with marine bacteria indicates scope for microbiome manipulation in Acropora tenuis and Platygyra daedalea. Front. Microbiol. 10:1702

39. Mathur V, del Campo J, Kolisko M, Keeling PJ. 2018. Global diversity and distribution of close relatives of apicomplexan parasites. Environ. Microbiol. 20(8):2824-33

40. Kwong WK, del Campo J, Mathur V, Vermeij MJA, Keeling PJ. 2019. A widespread coralinfecting apicomplexan with chlorophyll biosynthesis genes. Nature 568(7750):103-7

41. McFadden GI, Reith ME, Munholland J, Lang-Unnasch N. 1996. Plastid in human parasites. Nature 381(6582):482

42. Vohsen SA, Anderson KE, Gade AM, Gruber-Vodicka HR, Dannenberg RP, et al. 2020. Deep-sea corals provide new insight into the ecology, evolution, and the role of plastids in widespread apicomplexan symbionts of anthozoans. Microbiome 8:34

43. Robbins SJ, Singleton CM, Chan CX, Messer LF, Geers AU, et al. 2019. A genomic view of the reef-building coral Porites lutea and its microbial symbionts. Nat. Microbiol. 4(12):2090-100

44. Smith SM. 2018. Complementarity in the coral holobiont: a genomic analysis of bacterial isolates of Orbicella faveolata and Symbiodinium spp. [**AU: Please provide publication information**]

45. Agostini S, Suzuki Y, Higuchi T, Casareto BE, Yoshinaga K, et al. 2012. Biological and chemical characteristics of the coral gastric cavity. Coral Reefs 31:147-56

46. Hopkinson BM, Morel FMM. 2009. The role of siderophores in iron acquisition by photosynthetic marine microorganisms. Biometals 22:659-69

47. Reich HG, Rodriguez IB, LaJeunesse TC, Ho T-Y. 2020. Endosymbiotic dinoflagellates 
pump iron: differences in iron and other trace metal needs among the Symbiodiniaceae. Coral Reefs 39:915-27

48. Shick JM, Iglic K, Wells ML, Trick CG, Doyle J, Dunlap WC. 2011. Responses to iron limitation in two colonies of Stylophora pistillata exposed to high temperature: implications for coral bleaching. Limnol. Oceanogr. 56(3):813-28

49. Schalk IJ, Hannauer M, Braud A. 2011. New roles for bacterial siderophores in metal transport and tolerance. Environ. Microbiol. 13(11):2844-54

50. Barnes DJ. 1970. Coral skeletons: an explanation of their growth and structure. Science 170(3964):1305-8

51. Al-Horani F, M. Al-Moghrabi S, de Beer D. 2003. The mechanism of calcification and its relation to photosynthesis and respiration in the scleractinian coral Galaxea fascicularis. Mar. Biol. 142:419-26

52. Biscéré T, Ferrier-Pagès C, Grover R, Gilbert A, Rottier C, et al. 2018. Enhancement of coral calcification via the interplay of nickel and urease. Aquat. Toxicol. 200:247-56

53. Barnes DJ, Crossland CJ. 1976. Urease activity in the staghorn coral, Acropora acuminata. Comp. Biochem. Physiol. B 55(3):371-76

54. Villela HDM, Vilela CLS, Assis JM, Varona N, Burke C, et al. 2019. Prospecting microbial strains for bioremediation and probiotics development for metaorganism research and preservation. J. Vis. Exp. 152:e60238

55. Domart-Coulon IJ, Sinclair CS, Hill RT, Tambutté S, Puverel S, Ostrander GK. 2004. A basidiomycete isolated from the skeleton of Pocillopora damicornis (Scleractinia) selectively stimulates short-term survival of coral skeletogenic cells. Mar. Biol. 144(3):58392

56. Pernice M, Raina J-B, Rädecker N, Cárdenas A, Pogoreutz C, Voolstra CR. 2019. Down to the bone: the role of overlooked endolithic microbiomes in reef coral health. ISME J. $14: 325-34$

57. Fine M, Loya Y. 2002. Endolithic algae: an alternative source of photoassimilates during coral bleaching. Proc. Biol. Sci. 269(1497):1205-10

58. Jeong HJ, Du Yoo Y, Kang NS, Lim AS, Seong KA, et al. 2012. Heterotrophic feeding as a newly identified survival strategy of the dinoflagellate Symbiodinium. PNAS 109(31):12604 9

59. Lawson CA, Raina J-B, Kahlke T, Seymour JR, Suggett DJ. 2018. Defining the core microbiome of the symbiotic dinoflagellate, Symbiodinium. Environ. Microbiol. Rep. $10(1): 7-11$ 
60. Bernasconi R, Stat M, Koenders A, Huggett MJ. 2019. Global networks of Symbiodiniumbacteria within the coral holobiont. Microb. Ecol. 77(3):794-807

61. Matthews JL, Raina J, Kahlke T, Seymour JR, van Oppen MJH, Suggett DJ. 2020. Symbiodiniaceae-bacteria interactions: rethinking metabolite exchange in reef-building corals as multi-partner metabolic networks. Environ. Microbiol. 22(5):1675-87

62. Frommlet JC, Sousa ML, Alves A, Vieira SI, Suggett DJ, Serôdio J. 2015. Coral symbiotic algae calcify ex hospite in partnership with bacteria. PNAS 112(19):6158-63

63. Leite D, Salles JF, Calderon EN, Castro CB, Bianchini A, et al. 2018. Coral bacterial-core abundance and network complexity as proxies for anthropogenic pollution. Front. Microbiol. 9:833

64. Wear SL, Thurber RV. 2015. Sewage pollution: Mitigation is key for coral reef stewardship. Ann. N.Y. Acad. Sci. 1355(1):15-30

65. Weis VM. 2008. Cellular mechanisms of Cnidarian bleaching : Stress causes the collapse of symbiosis. J. Exp. Biol. 211:3059-66

66. Jain RK, Kapur M, Labana S, Lal B, Sarma PM, et al. 2005. Microbial diversity: application of microorganisms for the biodegradation of xenobiotics. Curr. Sci. 89(1):101-12

67. Cabiscol E, Tamarit J, Ros J. 2000. Oxidative stress in bacteria and protein damage by reactive oxygen species. $3(1): 3-8$

68. Gegner HM, Rädecker N, Ochsenkühn M, Barreto MM, Ziegler M, et al. 2019. High levels of floridoside at high salinity link osmoadaptation with bleaching susceptibility in the cnidarian-algal endosymbiosis. Biol. Open. 8(12):bio045591

69. Oakley CA, Davy SK. 2018. Cell biology of coral bleaching. In Coral Bleaching: Patterns Processes, Causes and Consequences, ed. MJH van Oppen, JM Lough, pp. 189-211. Ecol. Stud. 233. Cham, Switz.: Springer Nat. 1st ed.

70. Lesser MP. 1997. Oxidative stress causes coral bleaching during exposure to elevated temperatures. Coral Reefs 16(3):187-92

71. Diaz JM, Hansel CM, Apprill A, Brighi C, Zhang T, et al. 2016. Species-specific control of external superoxide levels by the coral holobiont during a natural bleaching event. Nat. Commun. 7:13801

72. Ochsenkühn MA, Röthig T, D’Angelo C, Wiedenmann J, Voolstra CR. 2017. The role of floridoside in osmoadaptation of coral-associated algal endosymbionts to high-salinity conditions. Sci. Adv. 3(8):e1602047

73. Gegner HM, Ziegler M, Rädecker N, Buitrago-López C, Aranda M, Voolstra CR. 2017. High salinity conveys thermotolerance in the coral model Aiptasia. Biol. Open 6(12):1943-48 
74. Ngugi DK, Ziegler M, Duarte CM, Voolstra CR. 2020. Genomic blueprint of glycine betaine metabolism in coral metaorganisms and their contribution to genomic blueprint of glycine betaine. iScience 23(5):101120

75. Murata N, Takahashi S, Nishiyama Y, Allakhverdiev SI. 2007. Photoinhibition of photosystem II under environmental stress. Biochim. Biophys. Acta 1767:414-21

76. Bailey S, Grossman A. 2008. Photoprotection in cyanobacteria: regulation of light harvesting. Photochem. Photobiol. 84(6):1410-20

77. Dunlap WC, Shick JM. 1998. Ultraviolet radiation-absorbing mycosporine-like amino acids in coral reef organisms: a biochemical and environmental perspective. J. Phycol. 34(3):41830

78. Banaszak AT, LaJeunesse TC, Trench RK. 2000. The synthesis of mycosporine-like amino acids (MAAs) by cultured, symbiotic dinoflagellates. J. Exp. Mar. Biol. Ecol. 249(2):219-33

79. Kirilovsky D, Kerfeld CA. 2012. The orange carotenoid protein in photoprotection of photosystem II in cyanobacteria. Biochim. Biophys. Acta 1817(1):158-66

80. Ragni M, Airs RL, Hennige SJ, Suggett DJ, Warner ME, Geider RJ. 2010. PSII photoinhibition and photorepair in Symbiodinium (Pyrrhophyta) differs between thermally tolerant and sensitive phylotypes. Mar. Ecol. Prog. Ser. 406:57-70

81. Osman EO, Suggett DJ, Voolstra CR, Pettay DT, Clark DR, et al. 2020. Coral microbiome composition along the northern Red Sea suggests high plasticity of bacterial and specificity of endosymbiotic dinoflagellate communities. Microbiome 8:8

82. Yost DM, Jones RJ, Mitchelmore CL. 2010. Alterations in dimethylsulfoniopropionate (DMSP) levels in the coral Montastraea franksi in response to copper exposure. Aquat. Toxicol. 98(4):367-73

83. Sunda W, Kieber DJ, Kiene RP, Huntsman S. 2002. An antioxidant function for DMSP and DMS in marine algae. Nature 418:317-20

84. Ritchie KB. 2006. Regulation of microbial populations by coral surface mucus and mucusassociated bacteria. Mar. Ecol. Prog. Ser. 322:1-14

85. Kvennefors ECE, Sampayo E, Kerr C, Vieira G, Roff G, Barnes AC. 2012. Regulation of bacterial communities through antimicrobial activity by the coral holobiont. Microb. Ecol. 63(3):605-18

86. Krediet CJ, Ritchie KB, Alagely A, Teplitski M. 2013. Members of native coral microbiota inhibit glycosidases and thwart colonization of coral mucus by an opportunistic pathogen. ISME J. 7(5):980-90

87. Raina JB, Dinsdale EA, Willis BL, Bourne DG. 2010. Do the organic sulfur compounds 
DMSP and DMS drive coral microbial associations? Trends Microbiol. 18(3):101-8

88. Raina JB, Tapiolas D, Motti CA, Foret S, Seemann T, et al. 2016. Isolation of an antimicrobial compound produced by bacteria associated with reef-building corals. PeerJ 2016(4):e2275

89. Garren M, Son K, Raina JB, Rusconi R, Menolascina F, et al. 2014. A bacterial pathogen uses dimethylsulfoniopropionate as a cue to target heat-stressed corals. ISME J. 8(5):9991007

90. Sharp KH, Ritchie KIMB. 2012. Multi-partner interactions in corals in the face of climate change. Biol. Bull. 223:66-77

91. Tait K, Hutchison Z, Thompson FL, Munn CB. 2010. Quorum sensing signal production and inhibition by coral-associated vibrios. Environ. Microbiol. Rep. 2(1):145-50

92. Zimmer BL, May AL, Bhedi CD, Dearth SP, Prevatte CW, et al. 2014. Quorum sensing signal production and microbial interactions in a polymicrobial disease of corals and the coral surface mucopolysaccharide layer. PLOS ONE 9(9):e108541

93. Certner RH, Vollmer SV. 2015. Evidence for autoinduction and quorum sensing in white band disease-causing microbes on Acropora cervicornis. Sci. Rep. 5:11134

94. Zhou J, Lin ZJ, Cai ZH, Zeng YH, Zhu JM, Du XP. 2020. Opportunistic bacteria use quorum sensing to disturb coral symbiotic communities and mediate the occurrence of coral bleaching. Environ. Microbiol. 22(5):1944-62

95. Modolon F, Barno AR, Villela HDM, Peixoto RS. 2020. Ecological and biotechnological importance of secondary metabolites produced by coral-associated bacteria. J. Appl. Microbiol. In press [**AU: As meant?**]

96. Barr JJ, Auro R, Furlan M, Whiteson KL, Erb ML, et al. 2013. Bacteriophage adhering to mucus provide a non-host-derived immunity. PNAS 110(26):10771-76

97. Efrony R, Loya Y, Bacharach E, Rosenberg E. 2007. Phage therapy of coral disease. Coral Reefs 26(1):7-13

98. Efrony R, Atad I, Rosenberg E. 2009. Phage therapy of coral white plague disease: properties of phage BA3. Curr. Microbiol. 58(2):139-45

99. Welsh RM, Rosales SM, Zaneveld JR, Payet JP, McMinds R, et al. 2017. Alien versus predator: Bacterial challenge alters coral microbiomes unless controlled by Halobacteriovorax predators. PeerJ 5:e3315

100. Pernthaler J. 2005. Predation on prokaryotes in the water column and its ecological implications. Nat. Rev. Microbiol. 3:537-47

101. Williams HN, Lymperopoulou DS, Athar R, Chauhan A, Dickerson TL, et al. 2015. 
Halobacteriovorax, an underestimated predator on bacteria: potential impact relative to viruses on bacterial mortality. ISME J. 491-99

102. Welsh RM, Zaneveld JR, Rosales SM, Payet JP, Burkepile DE, Thurber RV. 2016. Bacterial predation in a marine host-associated microbiome. ISME J. 10:1540-44

103. Nitschke MR, Davy SK, Ward S. 2016. Horizontal transmission of Symbiodinium cells between adult and juvenile corals is aided by benthic sediment. Coral Reefs 35(1):335-44

104. Leite D, Leão P, Garrido AG, Lins U, Santos HF, et al. 2017. Broadcast spawning coral Mussismilia hispida can vertically transfer its associated bacterial core. Front. Microbiol. $8: 176$

105. Sharp KH, Distel D, Paul VJ. 2012. Diversity and dynamics of bacterial communities in early life stages of the Caribbean coral Porites astreoides. ISME J. 6(4):790-801

106. Damjanovic K, Menéndez P, Blackall LL, van Oppen MJH. 2020. Mixed-mode bacterial transmission in the common brooding coral Pocillopora acuta. Environ. Microbiol. 22(1):397-412

107. Ceh J, Raina J-B, Soo RM, van Keulen M, Bourne DG. 2012. Coral-bacterial communities before and after a coral mass spawning event on Ningaloo Reef. PLOS ONE 7(5):e36920

108. Lema KA, Bourne DG, Willis BL. 2014. Onset and establishment of diazotrophs and other bacterial associates in the early life history stages of the coral Acropora millepora. Mol. Ecol. 23(19):4682-95

109. Negri AP, Webster NS, Hill RT, Heyward AJ. 2001. Metamorphosis of broadcast spawning corals in response to bacteria isolated from crustose algae. Mar. Ecol. Prog. Ser. 223:121-31

110. Sneed JM, Sharp KH, Ritchie KB, Paul VJ. 2014. The chemical cue tetrabromopyrrole from a biofilm bacterium induces settlement of multiple Caribbean corals. Proc. R. Soc. B Biol. Sci. 281(1786):20133086

111. Shikuma NJ, Antoshechkin I, Medeiros JM, Pilhofer M, Newman DK. 2016. Stepwise metamorphosis of the tubeworm Hydroides elegans is mediated by a bacterial inducer and MAPK signaling. PNAS 113(36):10097-102

112. Beckmann M, Harder T, Qian P-Y. 1999. Induction of larval attachment and metamorphosis in the serpulid polychaete Hydroides elegans by dissolved free amino acids: mode of action in laboratory bioassays. Mar. Ecol. Prog. Ser. 190:167-78

113. Lesser MP, Falcón LI, Rodríguez-Román A, Enríquez S, Hoegh-Guldberg O, IglesiasPrieto R. 2007. Nitrogen fixation by symbiotic cyanobacteria provides a source of nitrogen for the scleractinian coral Montastraea cavernosa. Mar. Ecol. Prog. Ser. 346:143-52

114. Rädecker N, Pogoreutz C, Voolstra CR, Wiedenmann J, Wild C. 2015. Nitrogen cycling in 
corals: The key to understanding holobiont functioning? Trends Microbiol. 23(8):490-97

115. Wiedenmann J, D’Angelo C, Smith EG, Hunt AN, Legiret FE, et al. 2013. Nutrient enrichment can increase the susceptibility of reef corals to bleaching. Nat. Clim. Change $3(2): 160-64$

116. Jaspers C, Fraune S, Arnold AE, Miller DJ, Bosch TCG, Voolstra CR. 2019. Resolving structure and function of metaorganisms through a holistic framework combining reductionist and integrative approaches. Zoology 133:81-87

117. Hosokawa T, Koga R, Kikuchi Y, Meng XY, Fukatsu T. 2010. Wolbachia as a bacteriocyteassociated nutritional mutualist. PNAS 107(2):769-74

118. Wada N, Ishimochi M, Matsui T, Pollock FJ, Tang SL, et al. 2019. Characterization of coral-associated microbial aggregates (CAMAs) within tissues of the coral Acropora hyacinthus. Sci. Rep. 9:14662

119. Login FH, Balmand S, Vallier A, Vincent-Monégat C, Vigneron A, et al. 2011. Antimicrobial peptides keep insect endosymbionts under control. Science 334:362-65

120. Jernigan KK, Bordenstein SR. 2015. Tandem-repeat protein domains across the tree of life. PeerJ 3:e732

121. Fan L, Reynolds D, Liu M, Stark M, Kjelleberg S, Webster NS. 2012. Functional equivalence and evolutionary convergence in complex communities of microbial sponge symbionts. PNAS. 109(27):1878-87

122. Nguyen MTHD, Liu M, Thomas T. 2014. Ankyrin-repeat proteins from sponge symbionts modulate amoebal phagocytosis. Mol. Biol. Evol. 23(6):1635-45

123. Reynolds D, Thomas T. 2016. Evolution and function of eukaryotic-like proteins from sponge symbionts. Mol. Ecol. 25:5242-53

124. Al-khodor S, Price CT, Habyarimana F, Kalia A, Kwaik YA. 2008. A Dot/Icm-translocated ankyrin protein of Legionella pneumophila is required for intracellular proliferation within human macrophages and protozoa. Mol. Microbiol. 70(4):908-23

125. Habyarimana F, Al-khodor S, Kalia A, Graham JE, Price CT, et al. 2008. Role for the Ankyrin eukaryotic-like genes of Legionella pneumophila in parasitism of protozoan hosts and human macrophages. Environ. Microbiol. 10(6):1460-74

126. Ogawa M, Bisson LF, García-Martínez T, Mauricio JC, Moreno-García J. 2019. New insights on yeast and filamentous fungus adhesion in a natural co-immobilization system: proposed advances and applications in wine industry. Appl. Microbiol. Biotechnol. 103(12):4723-31

127. Efremenko EN, Nikolskaya AB, Lyagin IV, Senko OV, Makhlis TA, et al. 2012. Production 
of biofuels from pretreated microalgae biomass by anaerobic fermentation with immobilized Clostridium acetobutylicum cells. Bioresour. Technol. 114:342-48

128. Bouabidi ZB, El-Naas MH, Zhang Z. 2019. Immobilization of microbial cells for the biotreatment of wastewater: a review. Environ. Chem. Lett. 17(1):241-57

129. Sun X, Meng J, Huo S, Zhu J, Zheng S. 2020. Remediation of heavy metal pollution in soil by microbial immobilization with carbon microspheres. Int. J. Environ. Sci. Dev. 11(1):4347

130. Sweet M, Ramsey A, Bulling M. 2017. Designer reefs and coral probiotics: Great concepts but are they good practice? Biodiversity 18(1):19-22

131. Willaert R. 2007. Cell immobilization and its applications in biotechnology: current trends and future prospects. In Fermentation Microbiology and Biotechnology, ed. EMT El-Masi, CFA Bryce, AL Demain, AR Allman, pp. 289-362. Boca Raton, FL: CRC Press

132. Nunes GS, Marty J-L. 2006. Immobilization of enzymes on electrodes. In Immobilization of Enzymes and Cells, ed. JM Guisan, pp. 239-50. Cham, Switz.: Springer Nat.

133. Zhang L-S, Wu W, Wang J. 2007. Immobilization of activated sludge using improved polyvinyl alcohol (PVA) gel. J. Environ. Sci. 19(11):1293-97

134. Mozes N, Marchal F, Hermesse MP, Van Haecht JL, Reuliaux L, et al. 1987. Immobilization of microorganisms by adhesion: interplay of electrostatic and nonelectrostatic interactions. Biotechnol. Bioeng. 30(3):439-50

135. Declerck SAJ, Papakostas S. 2017. Monogonont rotifers as model systems for the study of micro-evolutionary adaptation and its eco-evolutionary implications. Hydrobiologia 796:131-44

136. Rudtanatip T, Boonsri B, Praiboon J, Wongprasert K. 2019. Bioencapsulation efficacy of sulfated galactans in adult Artemia salina for enhancing immunity in shrimp Litopenaeus vannamei. Fish Shellfish Immunol. 94:90-98

137. Bengtson DA. 2003. Status of marine aquaculture in relation to live prey: past, present and future. Live Feed in Marine Aquaculture, ed. JG Støttrup, LA McEvoy, pp. 1-16. Oxford, UK: Blackwell

138. Melo-Bolívar JF, Ruiz-Pardo RY, Hume ME, Sidjabat HE, Villamil-Diaz LM. 2020. Probiotics for cultured freshwater fish. Microbiol. Aust. 41(2):105-8

139. Craggs J, Guest JR, Davis M, Simmons J, Dashti E, Sweet M. 2017. Inducing broadcast coral spawning ex situ: closed system mesocosm design and husbandry protocol. Ecol. Evol. 7:11066-78

140. Gibbin E, Gavish A, Domart-Coulon I, Kramarsky-Winter E, Shapiro O, et al. 2018. Using 
NanoSIMS coupled with microfluidics to visualize the early stages of coral infection by Vibrio coralliilyticus. BMC Microbiol. 18:39

141. Wein T, Dagan T, Fraune S, Bosch TCG, Reusch TBH, Hülter NF. 2018. Carrying capacity and colonization dynamics of Curvibacter in the Hydra host habitat. Front. Microbiol. 9:443

[**AU: These references seem to appear only in the supplemental table. If you choose not to add the supplemental table into the main text, are we okay to remove them?**]

142. Burriesci MS, Raab TK, Pringle JR. 2012. Evidence that glucose is the major transferred metabolite in dinoflagellate-cnidarian symbiosis. J. Exp. Biol. 215(19):3467-77

143. Davy SK, Allemand D, Weis VM. 2012. Cell biology of cnidarian-dinoflagellate symbiosis. Microbiol. Mol. Biol. Rev. 76(2):229-61

144. Tremblay P, Fine M, Maguer J-F, Grover R, Ferrier-Pagès C. 2013. Photosynthate translocation increases in response to low seawater $\mathrm{pH}$ in a coral-dinoflagellate symbiosis. Biogeosciences 10(6):3997-4007

145. Olson ND, Ainsworth TD, Gates RD, Takabayashi M. 2009. Diazotrophic bacteria associated with Hawaiian Montipora corals: diversity and abundance in correlation with symbiotic dinoflagellates. J. Exp. Mar. Biol. Ecol. 371(2):140-46

146. Lema KA, Willis BL, Bourneb DG. 2012. Corals form characteristic associations with symbiotic nitrogen-fixing bacteria. Appl. Environ. Microbiol. 78(9):3136-44

147. Kimes NE, Van Nostrand JD, Weil E, Zhou J, Morris PJ. 2010. Microbial functional structure of Montastraea faveolata, an important Caribbean reef-building coral, differs between healthy and yellow-band diseased colonies. Environ. Microbiol. 12(2):541-56

148. Webster NS, Smith LD, Heyward AJ, Watts JEM, Webb RI, et al. 2004. Metamorphosis of a scleractinian coral in response to microbial biofilms. Appl. Environ. Microbiol. 70(2):1213-21

149. Heyward AJ, Negri AP. 2010. Plasticity of larval pre-competency in response to temperature: Observations on multiple broadcast spawning coral species. Coral Reefs 29(3):631-36

150. Shikuma NJ, Pilhofer M, Weiss GL, Hadfield MG, Jensen GJ, Newman DK. 2014. Marine tubeworm metamorphosis induced by arrays of bacterial phage tail-like structures. Science 343(6170):529-33

Added references: 
Apprill, A., Marlow, H. Q., Martindale, M. Q., \& Rappé, M. S. (2009). The onset of microbial associations in the coral Pocillopora meandrina. The ISME Journal, 3(6), 685-699.

Oh, Y. S., Maeng, J., \& Kim, S. J. (2000). Use of microorganism-immobilized polyurethane foams to absorb and degrade oil on water surface. Applied microbiology and biotechnology, 54(3), 418-423. 